\title{
Uma análise da multidimensionalidade das percepções de justiça em um tipo ideal de economia solidária e nos empreendimentos econômicos solidários do Paraná*
}

\author{
An analysis of the multidimensionality of the fairness perceptions in an ideal type \\ of solidarity economy and in solidarity economic enterprises of Paraná
}

Oz Solon Chovghi Iazdi**

\begin{abstract}
Resumo: O artigo parte de uma crítica à concepção utilitarista e unidimensional de justiça utilizada pela economia neoclássica para propor a necessidade de se adotar uma abordagem comunitária e multidimensional desse conceito, incluindo noções distributivas, procedimentais e interacionais. Mostra-se que, em teoria, um tipo ideal de Economia Solidária provê maiores incentivos do que um tipo ideal de Economia Capitalista para a amplificação do senso de igualdade, democracia e solidariedade percebido pelos trabalhadores. Contudo, através da observação de dados do Sistema Nacional de Informações em Economia Solidária e de relatos em empreendimentos econômicos solidários do Paraná, evidencia-se que há, ainda, um compartilhamento de valores institucionais que se distanciam do que se espera de uma Economia Solidária ideal.
\end{abstract}

Palavras-chave: Percepções de justiça; Economia solidária; Democracia; Igualdade; Instituições

\begin{abstract}
The paper starts from a critique of the utilitarian and one-dimensional conception of fairness used by neoclassical economics to propose the need to adopt a communitarian and multidimensional approach to this concept, including distributional, procedural and interactional notions. It is shown that, in theory, an ideal type of Solidarity Economy provides greater incentives than an ideal type of capitalist economy for the amplification of the sense of equality, democracy and solidarity perceived by the workers. However, through the observation of data from the National Solidarity Economy Information System and reports from members of solidarity economic enterprises in Paraná, it is clear that there is still a sharing of institutional values that are far from what is expected from an ideal Solidary Economy.
\end{abstract}

Keywords: Fairness; Solidarity economy; Democracy; Equality; Institutions

JEL: B41, B55, D63, D71, J54, P13

\footnotetext{
*Submissão: 12/08/2019| Aprovação: 25/04/2020 | DOI: 10.5380/re.v42i77.68471

*** Universidade Estadual de Mato Grosso do Sul (UEMS) |E-mail: oz.iazdi@uems.br | ORCID: 0000-0002$2027-4426$

Esta publicação está licenciada sob os termos de

Creative Commons Atribuição-Não Comercial 4.0 Internacional
} 


\section{Introdução}

As ciências sociais são compostas de uma ampla variedade de disciplinas e áreas de estudo que, por sua vez, apresentam diversos paradigmas e quadros teóricos. Em grande medida, algumas vertentes teóricas se sobressaem sobre outras e definem, em determinado momento histórico, aquilo que é considerado mainstream em suas áreas, ou seja, aquilo que é ensinado nas universidades de maior prestígio, é publicado nas revistas científicas de maior prestígio, recebe financiamento das fundações de pesquisa mais importantes e ganha os melhores prêmios da área ${ }^{1}$. Especificamente em relação às ciências econômicas, pode-se afirmar que a escola de pensamento neoclássica faz parte do que é considerado mainstream atualmente, tendo como características centrais: a ênfase na racionalidade e a utilização da maximização de utilidade como um critério de racionalidade; a ênfase sobre o equilíbrio; a negligência sobre fortes tipos de incerteza (Dequech, 2007).

Diante da influência e do prestígio que a concepção neoclássica tem dentro das ciências econômicas, o primeiro objetivo do artigo é argumentar que tal concepção limita a análise de um dos elementos fundamentais na definição da coesão e legitimidade de uma estrutura socioeconômica: as percepções de justiça dos indivíduos. Mais especificamente, a economia neoclássica entende as percepções de justiça como um construto unidimensional, no qual a única dimensão relevante é a distribuição final dos bens para a determinação da satisfação e do bemestar social. Contudo, o utilitarismo imbricado na teoria neoclássica não é o único parâmetro de definição sobre o que é ou o que deve ser considerado justo, existindo um amplo espectro de fundamentos filosóficos que embasam diferentes concepções de justiça. Partindo-se do debate sobre essas diferentes visões de justiça, destaca-se, em especial, a contribuição do paradigma comunitário, da justiça organizacional e da psicologia social cognitiva, que permitem ampliar a concepção limitada sobre justiça da teoria utilitarista ao incorporar todas as dimensões relevantes: justiça distributiva, procedimental e interacional.

Baseando-se nessa concepção ampliada das percepções de justiça, o segundo objetivo do artigo é entender e comparar como essas três dimensões estão inseridas em um tipo ideal de Economia Capitalista (EC) e em um tipo ideal de modo de

\footnotetext{
1 Embora Dequech (2007) se refira especificamente à mainstream economics, utiliza-se aqui essa caracterização sociológica baseada na influência e no prestígio para estender a definição de mainstream para as outras áreas de estudo.
} 
produção não capitalista: as iniciativas de trabalhadores que integram a Economia Solidária (ES) em toda sua rede. Supõe-se que, ao menos em um construto analítico ideal weberiano, que serve de medida e comparação para os elementos empíricos da realidade (Weber, 2019), a ES proporciona uma estrutura de produção e distribuição mais igualitária, democrática e solidária do que a EC. Finalmente, como um terceiro objetivo, este artigo busca verificar se há alguma validade prática desse tipo ideal de ES a partir da percepção e relato dos próprios trabalhadores inseridos na ES. Para isso, utilizam-se os dados do Segundo Mapeamento Nacional de Empreendimentos Econômicos Solidários e também a observação de alguns estudos qualitativos com membros de Empreendimentos Econômicos Solidários (EES) do Paraná, procurando-se identificar como esses trabalhadores percebem, dentro desses empreendimentos, a justiça em suas três dimensões.

O artigo está organizado em seis seções, sendo a primeira composta por esta breve introdução. A Seção II discute a forma como as percepções de justiça são incorporadas pela teoria neoclássica e apresenta algumas concepções alternativas de justiça que são erigidas sobre fundamentos filosóficos não utilitaristas, com destaque para a concepção comunitária. Baseando-se no debate realizado na Seção II, a Seção III constrói, a partir das contribuições da justiça organizacional e da psicologia social cognitiva, uma concepção multidimensional das percepções de justiça, incorporando considerações sobre procedimentos e interações sociais, bem como abrindo a possibilidade para comportamentos que vão para além da maximização do bem-estar próprio. A partir dessa concepção ampliada da justiça, a Seção IV busca comparar em que medida os tipos ideais de uma Economia Capitalista e de uma Economia Solidária apresentariam condições para se verificar a presença (ou não) de ambientes de produção e trabalho percebidos como mais igualitários, democráticos e solidários. Na sequência, a Seção V busca confirmar, a partir de dados e pesquisas qualitativas com trabalhadores de EES do Paraná, a hipótese de que a estrutura de uma ES proporciona, na prática, uma percepção de altos níveis de justiça distributiva, procedimental e interacional. Por fim, a Seção VI discute o conteúdo desenvolvido ao longo do artigo e propõe alguns caminhos para a continuidade da investigação. 


\section{Os fundamentos filosóficos da justiça: a justiça utilitarista na economia neoclássica e algumas concepções alternativas}

A economia neoclássica insere as discussões sobre justiça social dentro da análise da economia do bem-estar que, por sua vez, está erigida sobre os fundamentos do utilitarismo. Mais especificamente, a economia neoclássica enxerga a percepção de justiça dos agentes econômicos através de lentes estreitas, definindo esse conceito de modo unidimensional, salientando apenas seu caráter distributivo. A partir disso, assume que as diferentes possibilidades de distribuição resultantes das preferências e escolhas individuais podem ser agregadas através de diversos formatos de equações de bem-estar social, sendo essas suficientes para circunscrever as discussões a respeito do que é - ou não é - justo. Por exemplo, supondo uma economia com apenas dois indivíduos, A e B, seus níveis de utilidade, $U_{A}$ e $U_{B}$, dependerão do quanto cada um deles consome dos bens e serviços disponíveis nessa economia. Os indivíduos, então, procurarão agir racionalmente no intuito de maximizar sua utilidade, respeitando as restrições orçamentárias, informacionais e institucionais.

O bem-estar social dessa economia, por sua vez, será dado por uma função do tipo $W=f\left(U_{A}, U_{B}\right)$. O formato dessa função estabelece diferentes possibilidades de ponderação entre as utilidades de A e B, de modo a definir um grau de bem-estar geral. Assim, podemos ter desde uma função que dá o mesmo peso às utilidades de cada um, como em $W=U_{A}+U_{B}$, até uma função que dá peso total à menor das utilidades, como em $W=\min \left(U_{A}, U_{B}\right)$. Como as discussões sobre justiça dentro desse quadro teórico são estabelecidas a partir do formato dessa função de bem-estar, tem-se, por construção, que a percepção do que é justo depende apenas da distribuição final de bens e serviços entre A e B e da utilidade final de cada um deles. Tal abordagem teórica pode ser observada nos principais manuais de microeconomia que geralmente servem de referência para os cursos de graduação e pós-graduação em economia (Mas-Colell et al., p. 825, 1995; Varian, p. 660, 2006) e que se pretendem explicar o comportamento dos agentes econômicos.

Apesar da posição de prestígio que a economia neoclássica e o utilitarismo gozam na teoria econômica, a justiça distributiva ${ }^{2}$ não se limita apenas a essa

\footnotetext{
${ }^{2}$ De acordo com Fleischacker (2006), "justiça social" e "justiça econômica" também são termos utilizados como sinônimos de "justiça distributiva" na literatura.
} 
concepção e fundamento filosófico. O próprio conceito de "justiça distributiva" sofreu alterações ao longo do tempo. Segundo Fleischacker (2006), o termo tem origem na obra de Aristóteles e se referia aos princípios segundo os quais as pessoas merecedoras teriam a garantia de ser recompensadas de acordo com seus méritos, sobretudo no que diz respeito a seu status político. Em seu sentido moderno, resultado dos ideais socialmente compartilhados após a Revolução Francesa, a justiça distributiva invoca o Estado para garantir que a propriedade seja distribuída de modo que todas as pessoas tenham acesso a um certo nível de recursos materiais.

Tomando-se como base o conceito moderno do termo sem ignorar, contudo, as contribuições dos pensadores pré-modernos, Michael Sandel (2012) destaca as principais concepções filosóficas que sustentam as teorias da justiça distributiva contemporâneas. Para além do utilitarismo de Jeremy Bentham que define uma moral de justiça baseada na maximização e agregação do bem-estar social através de um suposto cálculo de custo e benefício, Sandel destaca algumas das principais concepções contemporâneas de justiça, como a posição dos teóricos libertários (e.g. Friedrich Hayek, Milton Friedman e Robert Nozick), de Immanuel Kant, de John Rawls (contratualismo igualitário) e as visões dos críticos comunitários (e.g. Alasdair MacIntyre), incluindo sua própria concepção de justiça nesse último caso.

Os teóricos da concepção libertária defendem que a justiça social deve se fundamentar sobre a liberdade individual, de modo que rejeitam algumas diretrizes promulgadas pelo Estado moderno: as leis que protegem as pessoas contra si mesmas; o uso da força coerciva da lei para promover noções de virtude ou convicções morais da maioria dos cidadãos; a redistribuição de renda ou riqueza. Segundo Sandel (2012), a defesa do livre mercado realizada por pensadores como Hayek e Friedman não se assenta meramente em uma noção de eficiência econômica, mas na própria concepção de que a liberdade humana é a base da justiça. Robert Nozick (1974) vai além e repudia a própria noção de que a justiça distributiva consiste em um determinado padrão de distribuição específico (e.g. rendimentos igualitários, utilidade igualitária ou mesmo atendimento igualitário a necessidades semelhantes). Para ele, a justiça distributiva deve simplesmente atender a duas condições: garantir a origem legítima da propriedade individual e a justiça nas transferências e negociações. Algumas objeções podem ser feitas a essa concepção de justiça, como a negligência de reconhecer que os indivíduos 
possuem direitos materiais mínimos e, portanto, a necessidade de provisão de bens essenciais pelo Estado às pessoas mais pobres. Adicionalmente, não é possível refutar a crítica de que o nível de remuneração individual determinado pelo mercado não é definido apenas por uma questão de mérito, dado que alguns trabalhos recebem maiores remunerações por conta da sorte de serem reconhecidos pela sociedade em determinada época. Finalmente, dado que os libertários defendem que o indivíduo é dono de si mesmo, apresentam como resultado a aprovação de situações extremas, como a venda voluntária de órgãos humanos. Assim, entender a justiça com base em uma liberdade individual estritamente voltada ao mercado ou em termos utilitários degrada bens e práticas sociais que são regidos por normas e padrões mais elevados.

De acordo com Sandel (2012), Kant também associa a moralidade e a justiça à ideia de liberdade, embora fundamente sua concepção de liberdade para além da liberdade de escolha e transações de mercado. Segundo a concepção kantiana, tal liberdade não é verdadeira, pois envolve simplesmente a satisfação de desejos, vontades e preferências que, em última instância, não escolhemos. Kant argumenta que os seres humanos são merecedores de respeito e dignidade não por serem donos de si mesmos, mas por serem racionais e agirem com autonomia, isso é, agirem de acordo com leis auto impostas. Agir livremente não é escolher as melhores formas para atingir determinado fim, mas sim escolher os próprios fins. Além disso, são os motivos determinados racionalmente - e não as consequências - que dão valor moral à ação e que determinam o que é justo. Por exemplo, a transferência de renda para ajudar os mais pobres não será justa ou moral se for motivada por prazer ou compaixão, mas sim se a ajuda for motivada por um dever que comanda, racionalmente, a vontade do indivíduo. Tal dever se sustenta sobre o que Kant denomina de "imperativos categóricos" incondicionais e que definem uma ação como boa por si mesma. Para Kant, algo que poderia ter um valor absoluto como um fim em si mesmo é a humanidade. Portanto, na visão kantiana, a justiça social não deve se basear apenas em uma liberdade de escolhas mercadológicas definidas por desejos e preferências, mas em um contrato social imaginário que respeite a capacidade que os indivíduos têm de exercer a liberdade através da autonomia, respeitando os seres humanos como um fim em si mesmo (Sandel, 2012). 
Assim como Kant, John Rawls (1974) aborda a justiça distributiva com uma visão contratualista, embora fundamente sua concepção através de um liberalismo igualitário sustentado por dois princípios básicos: primeiro, cada pessoa tem um direito igual ao mais extensivo esquema de liberdades básicas (liberdade de pensamento, de religião, de escolha política); segundo, as desigualdades sociais e econômicas só devem existir: (a) para atingir o maior benefício esperado dos membros mais desfavorecidos da sociedade e (b) se estiverem relacionadas a cargos e posições abertas para todos sob condições de igualdade de oportunidades. Obedecendo esses dois princípios, os indivíduos devem formular um contrato social a partir de uma posição original em que devem se colocar sob um "véu de ignorância”. Isso significa que, para decidir a distribuição de bens e cargos de uma sociedade hipotética, cada pessoa deve realizar um exercício mental partindo do pressuposto de que não sabe, de início, qual posição assumirá nessa sociedade (qual será seu poder aquisitivo, sua visão política, suas crenças religiosas, etc.). Através desses princípios e condições, Rawls afirma que as desigualdades distributivas só serão justificadas se beneficiarem - direta ou indiretamente - o grupo de indivíduos mais necessitados. Como exemplo, os médicos poderiam receber uma remuneração maior do que outros profissionais se isso resultasse em um maior acesso aos serviços de saúde por parte da população mais pobre em comparação com o caso em que os médicos recebessem uma remuneração igual àquelas das outras profissões. Rawls nega que o merecimento ou a meritocracia sejam as melhores bases para determinar a justiça distributiva, visto que ele assume que as recompensas de mercado das aptidões naturais são tão arbitrárias do ponto de vista moral quanto a sorte de um indivíduo nascer em uma família de nobres em uma aristocracia feudal.

Ainda que reconheça a importância e os méritos das posições anteriores, Sandel (2012) realiza uma crítica a esses fundamentos de justiça distributiva a partir de uma concepção comunitária sustentada por uma visão aristotélica de justiça. Particularmente, ele argumenta que a justiça é teleológica, ou seja, para definir direitos é preciso saber qual a finalidade e propósito da prática social em questão. Além disso, a justiça tem um caráter honorífico, o que significa que compreender o propósito de uma prática social significa, ao menos em parte, compreender as virtudes que tal prática deve honrar e recompensar. A implicação dessa concepção de justiça é que, para determinar se as práticas sociais são justas e morais, é necessário definir seus objetivos e, de modo geral, definir o que é uma 
vida boa e quais virtudes cívicas devem ser exaltadas. Sandel vai além e determina que essas definições só podem ser realizadas de modo político, através de um constante debate público participativo e democrático que não ignore os laços e as identidades que definem e circunscrevem uma determinada comunidade. Desse modo, Sandel defende que não é possível conceber a justiça social com base apenas em um conceito de liberdade e neutralidade ou como uma função da busca pela maximização do bem-estar coletivo. Tomando emprestado a concepção de "narrativa" de Alasdair MacIntyre, Sandel ressalta que o aspecto teleológico da reflexão moral está ligado à condição de membro pertencente ao grupo do qual o indivíduo faz parte. Em outras palavras, as pessoas são portadoras de uma identidade que tem origem em uma narrativa da vida, definida em um momento e um local específico. Como consequência, as obrigações de solidariedade - que não requerem um consentimento - devem ser reconhecidas como uma categoria de responsabilidade moral. Uma pessoa deve tratar as outras com respeito e justiça não apenas por reconhecer no outro um ser racional, mas por compartilhar uma determinada história de vida.

Nota-se que a concepção utilitarista, apesar do prestígio que goza nas ciências econômicas, não é a única fundamentação filosófica que sustenta uma visão sobre a justiça social. A seção seguinte ressalta a contribuição da justiça organizacional e da psicologia social no sentido de ampliar ainda mais esse conceito de justiça, incorporando noções a respeito da percepção de justiça procedimental e interacional.

\section{Justiça como um conceito multidimensional: distribuição, procedimentos e interações}

Apesar da relevância e da ampla discussão teórica e normativa a respeito do conceito de justiça distributiva, desde a década de 1970 alguns teóricos de justiça organizacional e psicólogos sociais (Thibaut et al., 1974; Leventhal, 1976; Folger, 1977) têm dado atenção a um outro aspecto da justiça: a justiça procedimental (ou procedural). Esse tipo de concepção traz para o centro da discussão o próprio procedimento de decisão de uma distribuição de bens como sendo um importante aspecto para a percepção do que é justo (ou não) em dada sociedade. Isso significa que, independentemente da distribuição final dos bens em determinada interação social, os indivíduos também se importam com o procedimento e com a forma com 
que ocorre essa distribuição. Em geral, as pessoas preferem ter algum tipo de voz e participação na decisão distributiva, preferindo processos mais democráticos do que ditatoriais.

A dimensão da justiça procedimental amplia a concepção de bem-estar social focada apenas nos resultados utilitaristas, pois reconhece que as ações e processos também são relevantes para a determinação do bem-estar. As próprias escolhas e metas dos indivíduos podem refletir considerações que não envolvem a busca pelo seu próprio bem-estar, mas por padrões específicos de justiça social. Assim, não seria possível utilizar apenas uma ponderação das funções de utilidade dos indivíduos para a determinação do bem-estar ao se considerar as percepções de justiça procedimental, pois apenas os resultados finais importam nessas funções, não sendo sensíveis a diferentes procedimentos, caso esses levem aos mesmos resultados distributivos. Adicionalmente, a concepção utilitarista não considera diferentes motivações de ação para além da busca de uma satisfação autocentrada.

Na década de 1980, não satisfeitos com uma construção já ampliada da percepção de justiça, Bies e Shapiro (1987) adicionaram mais uma dimensão com a noção de justiça interacional. Eles afirmaram que as pessoas não se importam apenas com a distribuição de bens e seus procedimentos, mas também com a forma pela qual são tratadas por terceiros, gerando princípios de justiça calcados em questões como confiança e dignidade humana.

O resultado dessas contribuições é a construção de um conceito multidimensional de justiça que desafia a noção estreita e limitada da teoria neoclássica. Ainda que seja possível propor uma endogeneização de preferências procedimentais e interacionais na função de utilidade - e, consequentemente, na função de bem-estar social -, ampliando a concepção de justiça sem abandonar os preceitos metodológicos e o rigor matemático neoclássico, não é possível ignorar que as percepções de justiça dependem das regras de pensamento e comportamento que são socialmente compartilhadas e que possuem alguma recorrência ao longo do tempo, isso é, dependem das instituições (Dequech, 2013). Isso insere uma camada normativa e social que fragiliza uma construção utilitarista calcada em um individualismo metodológico. Em outras palavras, deve-se reconhecer que as instituições podem exercer uma influência legitimadora e profunda nos indivíduos que vão para além do que eles incorporam em um cálculo racional de maximização da própria utilidade. Tal concepção pode ser descrita pela ação baseada em 
comprometimento colocada por Sen (1977), diferenciando-se da ação baseada em simpatia, que deve obedecer aos axiomas neoclássicos e que possui três características limitadoras: julga os atos apenas pelas consequências; é uma abordagem de avaliação de atos ao invés de regras; as únicas consequências consideradas ao avaliar os atos são aquelas de interesse próprio.

Em um trabalho mais recente, Sen (2005) também aponta que os modelos tradicionais de comportamento racional obedecem, em geral, a três axiomas de bem-estar, meta e escolha centrados no indivíduo:

a) Bem-estar autocentrado: o bem-estar de uma pessoa depende apenas de seu próprio consumo, o que elimina tanto a possibilidade de simpatia ou antipatia em direção aos outros, como também os efeitos dos procedimentos e preocupações relacionais sobre o próprio bem-estar;

b) Meta de bem-estar próprio: A única meta do indivíduo é maximizar seu próprio bem-estar, o que elimina a possibilidade de incorporação de outras considerações nos próprios objetivos do indivíduo (como o bemestar dos outros), exceto nos casos em que elas influenciam o próprio bem-estar do indivíduo;

c) Escolha da própria meta: As escolhas de um indivíduo devem ser baseadas na busca de suas próprias metas, o que elimina a possibilidade desse indivíduo se restringir pelo reconhecimento das metas das outras pessoas, exceto nos casos em que essas outras metas moldam as próprias metas do indivíduo.

Segundo Sen (2005), enquanto a ação baseada em simpatia viola o primeiro axioma, não necessariamente viola os outros dois. Já a ação baseada em comprometimento não precisa violar necessariamente o primeiro axioma, mas pode violar todos eles. Por exemplo, a meta do indivíduo pode incluir objetivos outros que não a maximização do seu próprio bem-estar, como a busca por sua concepção de justiça social, incluindo a justiça procedimental e interacional. Além disso, sua escolha de comportamento pode ser restringida ou influenciada pelas metas dos outros ou por regras de conduta, ou seja, pelas instituições. Esses casos têm como consequência a violação do segundo e do terceiro axioma.

Tais exemplos mostram que a ampliação da concepção de justiça e as influências institucionais não podem ser plenamente descritas pela função de bemestar neoclássica e pela concepção utilitarista de justiça distributiva. Argumentase que, para além da incorporação teórica da justiça procedimental e interacional, 
a adoção de uma concepção comunitária da justiça distributiva proposta por Sandel (2012) vai ao encontro do objetivo de construir um conceito de justiça multidimensional, que respeita a diversidade de motivações para a ação e que ressalta a influência institucional através do reconhecimento de que a percepção de justiça é definida em um contexto local e temporal específico. Particularmente, reconhece-se que a percepção de justiça não pode ser separada da história compartilhada entre os indivíduos de uma determinada comunidade, o que inclui tanto as normas e convenções sociais como as próprias obrigações de solidariedade entre essas pessoas.

\section{A multidimensionalidade da justiça em tipos ideais de economia capitalista e economia solidária}

Mediante esse processo de ressignificação da justiça como um construto teórico ampliado, intenta-se verificar como os aspectos multidimensionais da justiça se encontram na concepção ideal de uma Economia Capitalista e de uma Economia Solidária. A importância dessa análise não é apenas reforçar a necessidade de mudança no marco teórico e metodológico prevalecente no que diz respeito às percepções de justiça na economia, mas também ressaltar como as organizações econômicas e sociais alternativas àquelas tipicamente capitalistas se apresentam como soluções ao enfrentamento da crescente desigualdade e do viés antidemocrático das instituições de justiça contemporâneas. Assim, partir com a unidimensionalidade da justiça se torna um pré-requisito para uma comparação mais refinada de modos de produção e distribuição distintos no que diz respeito à verificação de um senso socialmente compartilhado de igualdade, democracia e cooperação solidária.

Segundo Gaiger (2009), a Economia Solidária refere-se ao conjunto de iniciativas que visam não apenas o ganho econômico, mas a qualidade de vida e a participação cidadã através de associações livres e democráticas entre os trabalhadores. Como princípio, tais iniciativas buscam minimizar a presença de relações sociais que subentendem alguma separação entre capital e trabalho, como a disponibilização para o uso comum dos meios de produção e o processo de gestão participativa e democrática. As organizações de ES também procuram motivar seus membros a se engajarem ativamente nos problemas da comunidade e em lutas coletivas mais amplas, como o compartilhamento de valores de solidariedade e a 
busca pela sustentabilidade na utilização dos recursos naturais. Para Laville (2001), a Economia Solidária é importante ao ressaltar não apenas a lógica mercantil baseada na concorrência de indivíduos centrados no interesse próprio, mas também os outros princípios de interação que compõem o conjunto de práticas da dinâmica econômica: o da redistribuição dos bens e o da reciprocidade.

As iniciativas de Economia Solidária, sejam elas associações e cooperativas com marco institucional legal, sejam unidades informais e comunidades autóctones, são reunidas sob o conceito de Empreendimentos Econômicos Solidários. Segundo o texto de referência da III Conferência Nacional de Economia Solidária elaborado pelo Ministério do Trabalho e Emprego, os ESS devem possuir as seguintes características:

I. ser uma organização coletiva, singular ou complexa, cujos participantes ou sócios(as) são trabalhadoras(es) do meio urbano ou rural; II. realizar atividades de natureza econômica, socioambiental e cultural que devem ser as razões primordiais da existência da organização; III. ser uma organização de autogestão cujos participantes ou sócios exerçam coletivamente a gestão das atividades econômicas e a decisão sobre a partilha dos seus resultados, através da administração transparente e democrática, soberania da assembleia e singularidade de voto dos sócios, cumprindo o seu estatuto ou regimento interno; IV. ser uma organização permanente, considerando tanto os empreendimentos que estão em funcionamento quanto aqueles que estão em processo de implantação, desde que o grupo esteja constituído e as atividades econômicas definidas (Brasil, 2014, p. 15).

Diante das inúmeras características que definem a EC e a ES, a utilização de tipos ideais weberianos é um instrumento heurístico que permite combinar um conjunto de aspectos selecionados pelo investigador e que apresentam uma relação lógica a uma classe de fenômenos, sendo abstratos por natureza (Weber, 2019). Embora tal instrumento funcione apenas como uma imagem mental idealizada do fenômeno estudado, ele serve como medida de comparação e referência para o fenômeno que se observa na realidade, permitindo esclarecer alguns dos seus elementos empíricos. Gaiger et al. (2015) utilizaram os tipos ideais para realizar uma tipologia de Empreendimentos Econômicos Solidários no Brasil, identificando suas características fundamentais. Cruz (2009) também utiliza o tipo ideal para identificar os elementos essenciais das Redes de Economia Solidária, abrangendo não apenas os EES, como também a participação dos demais atores envolvidos, como o governo e as universidades. O objetivo nesta seção é tipificar idealmente a Economia Solidária e a Economia Capitalista a partir de alguns 
elementos orgânicos a esses dois sistemas que servem como possíveis pontos de comparação e diferenciação no que diz respeito às percepções de justiça dos indivíduos inseridos nessas economias. Em comparação com os trabalhos de Gaiger et al. (2015) e Cruz (2009), os tipos ideais construídos neste estudo são macroestruturais e se referem aos dois sistemas econômicos (ES e EC), portanto sendo mais abrangentes por natureza, ainda que as características dos EES e das Redes de Economia Solidária levantadas pelas duas investigações anteriores acabem por definir, em grande parte, o tipo ideal da ES, visto que os EES e os autores participantes das Redes são, por si mesmos, unidades centrais de tal sistema econômico.

\section{Quadro 1 - Características dos tipos ideais de Economia Capitalista e Economia Solidária.}

\begin{tabular}{|c|c|c|}
\hline & \multicolumn{2}{|c|}{ Tipos Ideais de Modos de Produção e Distribuição } \\
\hline Características & Economia Capitalista & Economia Solidária \\
\hline Tipo de propriedade & Propriedade privada & $\begin{array}{l}\text { Propriedade coletiva ou } \\
\text { associada }\end{array}$ \\
\hline Tipo de interação social & $\begin{array}{c}\text { Competição e interesse } \\
\text { próprio }\end{array}$ & Cooperação e confiança \\
\hline Finalidade & Valorização do capital & Garantia de bem-estar mínimo \\
\hline Domínios de provisão & Mercado & $\begin{array}{l}\text { Mercado e trocas não- } \\
\text { monetárias }\end{array}$ \\
\hline Unidade de produção & Empresa Capitalista & $\begin{array}{l}\text { Empreendimento Econ. } \\
\text { Solidário }\end{array}$ \\
\hline Remunerações & Salários / Lucros & Retiradas / Sobras \\
\hline Tipo de gestão & Heterogestão & Autogestão \\
\hline $\begin{array}{c}\text { Base de justiça } \\
\text { distributiva }\end{array}$ & Foco na equidade - mérito & Foco na igualdade - necessidade \\
\hline
\end{tabular}

Fonte: Elaboração própria.

Sendo assim, as características que permitem definir tipos ideais de ES e EC foram extraídas não apenas das tipificações de EES e Redes, mas principalmente do trabalho de análise teórica e macroestrutural realizada por Singer (2002). A partir da contribuição deste autor, nota-se que a ES se estrutura sobre algumas características fundamentais que a diferencia de uma concepção de EC. O Quadro 1 mostra um comparativo das diferenças entre o que seriam tipos ideais de ES e EC. Algumas das características contidas neste Quadro refletem aspectos que dizem respeito às dimensões de justiça, de modo que é possível 
observar como cada tipo ideal de estrutura econômica provê diferentes incentivos às percepções individuais.

No que se refere à questão distributiva, nota-se que a EC se baseia na propriedade privada e possui um foco elevado na equidade, ou seja, em uma noção de mérito onde cada um recebe em proporção àquilo que contribui para a produção, havendo diferença remunerativa entre tipos diferentes de trabalhos ou cargos. Em contraposição, a ES se baseia na propriedade coletiva ou associada, ressaltando um foco na igualdade distributiva e na necessidade de seus membros. Com base nessas características, percebe-se o padrão de diferenciação em classes sociais típico do sistema capitalista, resultando em uma distribuição funcional da renda entre salários e lucros, ou seja, entre a remuneração do capital e a remuneração da força de trabalho ${ }^{3}$. Apesar de o foco distributivo ser no mérito, tal sistema leva as classes favorecidas a possuírem vantagens cumulativas ao longo do tempo, o que contribui para o crescente aumento da desigualdade de renda entre os mais pobres e os mais ricos (Piketty, 2014). A ES, por sua vez, parte de um princípio distributivo de igualdade sustentado a partir de um tipo de propriedade coletiva ou associada. Em teoria, nesse tipo de organização, as pessoas são remuneradas de modo mais igualitário, com um foco maior na provisão das necessidades mínimas de todos os membros do grupo ou pagamento por hora trabalhada, sem diferenciação de cargos. Além disso, na ES há um enfoque no constante aprendizado técnico e educacional dos seus participantes, promovendo uma democratização do conhecimento e também das condições de capacitação técnica para além dos serviços oferecidos pelo Estado. Essa estrutura distributiva da ES provê condições para diminuir as desigualdades de oportunidades ao coletivizar os custos com o capital humano, promovendo capacitação a trabalhadores que estão à margem das políticas públicas ou que não recebem oportunidades de capacitação e ascensão na hierarquia de uma empresa capitalista típica. Como apontam Lustig et al. (2016) e Lee e Lee (2018), a redução na desigualdade dos anos de escolaridade e da qualificação formal, bem como o aumento da oferta de trabalhadores com maiores habilidades técnicas foram fatores fundamentais para a diminuição da desigualdade de renda na década passada, em especial no Brasil e na América

\footnotetext{
${ }^{3}$ Como forma de simplificar a análise, considera-se aqui a terra e o capital financeiro como subcategorias do capital, de modo que não se faz necessário uma distinção entre lucros, juros e aluguéis.
} 
Latina. Assim, é de se esperar que as pessoas tenham uma percepção de justiça distributiva mais igualitária em um tipo ideal de ES.

Quanto à justiça procedimental, a principal característica que reflete essa dimensão da justiça é o tipo de gestão da unidade de produção. A EC se baseia na heterogestão, onde os processos e procedimentos são realizados de forma hierárquica, sendo que as dúvidas e informações são requisitadas de baixo para cima e as ordens fluem de cima para baixo. Isso significa que, como regra geral, os trabalhadores não possuem voz e poder de decisão nos processos mais importantes e que definem os próprios resultados distributivos. Por outro lado, a ES tem como princípio a autogestão, onde todos os membros possuem poder de voto, de influência ou, ao menos, uma possibilidade clara de expressar sua opinião nos processos de produção e distribuição mediante reuniões, assembleias e comitês.

Através de um questionário realizado em mais de 500 domicílios na Suíça e na Alemanha, Frey e Pommerehne (1993) mostraram que as pessoas, em geral, observam o sistema de preços como um procedimento de alocação de recursos menos justo do que um processo baseado na tradição (no caso, a ideia de que "os primeiros a chegar, são os primeiros a se servir") ou em uma alocação administrativa, levada a cabo por regras determinadas pelo governo ou por uma administração central. Apenas um processo baseado na sorte foi considerado mais injusto que o sistema de mercado. Frey e Stutzer (2000) realizaram um estudo empírico e demonstraram que as pessoas auto reportaram um bem-estar subjetivo maior nos cantões da Suíça nos quais a participação democrática era maior. Os autores evidenciaram que fatores institucionais relacionados ao aumento da participação democrática podem influenciar mais do que as variáveis demográficas e econômicas no bem-estar individual. Anand (2001) enviou questionários para mais de 600 pessoas na Inglaterra no intuito de comprovar a importância da justiça procedimental na escolha dos indivíduos. Ele também constatou que as pessoas acreditam que processos baseados na sorte não são muito justos, e observou uma preferência por processos baseados em negociações. Mesmo quando as pessoas deveriam optar entre um processo baseado apenas em questões técnicas ou em um processo baseado em discussões, a maioria optou pela linha conjunta da discussão e negociação, ou seja, por processos de decisão em que participam ou possuem alguma voz. 
Diante dessas evidências, espera-se que, na prática, a percepção de justiça procedimental dos participantes de Empreendimentos Econômicos Solidários seja mais elevada do que a percepção dos trabalhadores de uma típica empresa capitalista, pois tomam decisões participativas e com direito a voto através de assembleias e comitês, unidos sob uma administração conjunta de associações e cooperativas.

Finalmente, no que diz respeito à justiça interacional, percebe-se que a EC se baseia em interações sociais que se fundamentam na busca pelo interesse próprio e no incentivo à competição, ao passo que a ES provê incentivos à cooperação solidária e à presença de confiança entre seus membros. Adicionalmente, a EC tem como principal domínio de provisão o mercado, enquanto a ES destaca a importância tanto do mercado quanto de trocas nãomonetárias, incluindo a economia doméstica. Assim, a estrutura capitalista tende a gerar uma maior saliência de conflitos do que a solidária. Como mostra Molm et al. (2006), quanto maior for a saliência de conflitos, menor será a percepção de justiça interacional advinda das trocas, o que influencia também na redução da percepção de justiça das duas outras dimensões. Em termos gerais, espera-se que o espírito cooperativo solidário e de confiança gere uma percepção de que as pessoas são tratadas de maneira mais digna e respeitosa dentro da ES do que da EC, elevando a percepção de justiça interacional entre os trabalhadores dos EES.

\section{Percepções de Justiça em Empreendimentos Econômicos Solidários do Paraná}

Embora a análise de uma estrutura típica ideal de Economia Solidária sugira que esta proveja incentivos a uma percepção de justiça mais igualitária, solidária e democrática por parte de seus membros do que os incentivos providos por um tipo ideal de Economia Capitalista, é necessário recorrer à observação empírica no intuito de verificar em que dimensão a teoria se traduz na prática. Partindo-se dos dados do Segundo Mapeamento Nacional de Empreendimentos Econômicos Solidários realizado em 2013 e disponibilizado pelo Sistema Nacional de Informações em Economia Solidária (SIES) e também de uma série de estudos que lançam mão de metodologias predominantemente qualitativas - em sua maioria, estudos de casos que utilizam questionários, relatos e entrevistas - para levantar as opiniões e percepções dos membros de Empreendimentos Econômicos Solidários 
do Paraná, esta seção tem por objetivo identificar o quanto as múltiplas dimensões das percepções de justiça são aderentes ao que se esperaria de uma ES.

De acordo com os dados do SIES, havia 832 EES no Paraná entre 2009 e 2013, sendo 361 associações, 137 cooperativas, 331 grupos informais e 3 sociedades mercantis. Algumas perguntas realizadas no Segundo Mapeamento Nacional de Empreendimentos Econômicos Solidários ajudam a ilustrar a posição relativa do Paraná no que se refere à busca e conquista de uma iniciativa de produção e organização mais igualitária, democrática e solidária, refletindo a multidimensionalidade da justiça. Comparando os EES do Paraná com os EES do Brasil (19.708 EES) e dos demais estados da Região Sul (Rio Grande do Sul, com 1.696 EES e Santa Catarina com 764 EES), observa-se que o motivo mais citado que levou à criação dos EES foi a busca de uma fonte de renda complementar tanto para o Paraná quanto para RS, SC e o restante do Brasil. No entanto, é interessante notar que apenas $21 \%$ dos EES do Paraná responderam que o desenvolvimento comunitário de capacidades e potencialidades motivou a criação das iniciativas solidárias, ao passo que esse número é de $22 \%$ para os demais estados do Sul e de $29 \%$ para o Brasil. Embora tal percentual possa indicar que há uma motivação inferior no Paraná no que diz respeito ao fortalecimento dos laços comunitários através da capacitação dos seus membros, 44\% dos EES deste estado afirmaram que o desenvolvimento de uma atividade onde todos são donos foi um fator de motivação da criação desses EES. Esse número é inferior para o Brasil (41\%) e para SC e RS (37\%), o que pode indicar que, ao menos em termos de intenção, os empreendimentos solidários do Paraná visavam ser uma alternativa contra uma estrutura distributiva e participativa injusta e hierárquica.

Observando-se as principais conquistas: 54\% dos EES do Paraná reportaram que tiveram sucesso em promover a autogestão e o exercício da democracia, enquanto esse indicador é de $49 \%$ para o Brasil e $45 \%$ para RS e SC; $68 \%$ no Paraná afirmaram melhorar a integração do grupo/coletivo, nível levemente superior que os indicadores do Brasil (66\%) e RS e SC (67\%); 44\% no Paraná indicaram a melhoria do comprometimento social dos membros, significativamente maior do que os números do Brasil (37\%) e os demais estados do Sul (38\%); finalmente, 20\% dos EES do Paraná reportaram atingir uma melhoria na conscientização e compromisso político, como a emancipação dos trabalhadores ou outras lutas mais gerais, indicador levemente superior ao do 
Brasil (18\%) e do RS e SC (19\%). Em geral, esses indicadores ajudam a mostrar não apenas um percentual de sucesso relativo maior nos EES do Paraná, mas permitem ilustrar que os membros dos empreendimentos solidários reconhecem como conquistas relevantes alguns elementos que permitem elevar a integração da comunidade, engendrando um aumento da participação em processos de gestão democrática e também fortalecendo o aspecto da justiça interacional através de comprometimentos sociais, integração e conscientização.

Apesar das conquistas, os EES do Paraná ainda enxergam como principais desafios: efetivar a participação e a autogestão (49\%); alcançar conscientização e politização dos seus membros (36\%); elevar a articulação com outros empreendimentos e o movimento da Economia Solidária (45\%); manter a união do grupo/coletivo (65\%). Todos esses quatro indicadores são maiores nos EES do Paraná do que considerando o total do Brasil (44\%, 34\%, 43\% e 56\%, respectivamente) e os números consolidados para RS e SC $(37 \%, 25 \%, 40 \%$ e $58 \%$, respectivamente). Adicionalmente, há um percentual mais elevado de EES no Paraná que possuem uma periodicidade semestral ou maior na realização de assembleias ou reuniões do coletivo de sócios (34\%), ao passo que esse percentual é menor para o Brasil (19\%) e para RS e SC (30\%). Reuniões mais recorrentes ajudariam a melhorar a autogestão e a percepção de justiça procedimental. Esses indicadores relativizam as conquistas e a posição de sucesso dos EES do Paraná, apontando para o reconhecimento de que ainda há grandes desafios no sentido de fortalecer a justiça em seus aspectos distributivos, procedimentais e interacionais, bem como estabelecer o senso de comunidade entre os membros e buscar transformações institucionais que estimulem os valores e princípios da ES.

Para além dessa macrovisão dos EES do Paraná, diversos estudos de caráter qualitativo permitem observar, através de entrevistas e questionários, as percepções de justiça dos membros de EES específicos desse estado. Oliveira et al. (2016) realizaram entrevistas semiestruturadas, acompanhamentos observacionais e levantamento de dados através de atas, estatutos, relatórios e planilhas de três cooperativas de catadores de resíduos sólidos em Maringá denominadas de Cooperativas A, C e I - que surgiram da iniciativa política de atendimento às exigências legais do tratamento desses resíduos. Em relação ao aspecto participativo e interacional, observou-se que em todas as cooperativas há certo individualismo no trabalho. Na Cooperativa $\mathrm{A}$, havia pouca participação 
entre os membros e apenas alguns traços de solidariedade e cooperação. A Cooperativa $\mathrm{C}$ apresentou um maior nível de participação dos membros, embora com alguma centralização nas pessoas com maior tempo de trabalho na cooperativa. Já a Cooperativa I demonstrou pouca participação, centralização, clima de desânimo e nenhum traço de solidariedade, sendo também a mais desestruturada em termos físicos e econômicos. Os autores ressaltaram que, embora as cooperativas realizassem eleições a cada dois anos e o peso dos votos entre os membros fossem iguais, o princípio de autogestão poderia ser questionado, dado que o grau de participação dos envolvidos era desigual, em grande parte por conta da falta de vontade de assumir maiores responsabilidades. No caso da Cooperativa I, os membros não ficaram à vontade para conversar sobre autogestão. Segundo os pesquisadores, isso "parece indicar duas coisas, primeiro a insegurança em relação ao significado de "autogestão" não estar claro para os entrevistados; e segundo, o possível distanciamento dessas organizações em relação aos princípios inerentes à autogestão. O grupo não percebe a ES” (p.91). Finalmente, em relação à distribuição dos ganhos, a receita gerada era distribuída de forma equitativa, seguindo critérios estabelecidos democraticamente e que levavam em conta o tempo de trabalho e o volume de material coletado. Essas características indicam um distanciamento prático dos incentivos teóricos às justiças interacional e procedimental - e a justiça distributiva, em um grau menor - que poderiam surgir a partir de uma ES exemplar. Os membros das três cooperativas não entendiam o empreendimento como uma possibilidade alternativa de fomentar uma estrutura socioeconômica de desenvolvimento sustentável a longo prazo sob os princípios da ES, uma meta de caráter coletivo e comunitário. Eles viam as cooperativas como uma alternativa insatisfatória e temporária para conseguirem alguma renda, até que surgisse a possibilidade de um registro formal no mercado de trabalho.

Mazzei e Crubellate (2011) também realizaram uma pesquisa através de aplicação de questionários e entrevistas com membros de duas cooperativas de reciclagem de Maringá: Cocarema e CooperMaringá. As duas cooperativas apresentaram bons indicadores no que diz respeito à participação dos trabalhadores em reuniões, debates e assembleias. No entanto, no quesito transparência, ambas apresentaram características negativas, com pouca divulgação das ações administrativas e produtivas, bem como ausência de planejamentos e fiscalização das contas, o que pode gerar percepções de injustiça procedimental. Em termos 
distributivos, as duas cooperativas tiveram bons resultados, visto que não se observou diferenças salariais dentro dos empreendimentos e as decisões tomadas em relação a esse aspecto eram tomadas sempre em conjunto. Em termos de relações comunitárias, a Cocarema e a CooperMaringá apresentaram boas relações com toda a sua rede de Economia Solidária, incluindo as parcerias com a Universidade Estadual de Maringá e os projetos com a Petrobrás e Banco do Brasil. Por outro lado, demonstraram pouco envolvimento com o poder público. Duas diferenças significativas entre elas que afetaram seus níveis relativos de percepção de justiça procedimental e interacional são a composição das lideranças e a formação média dos cooperados. A CooperMaringá teve em sua história lideranças essencialmente femininas que valorizavam mais os aspectos de relacionamento e bem-estar do grupo, ao passo que a Cocarema teve, até o momento em que a pesquisa foi realizada, um único líder masculino de personalidade forte e dinâmica, que priorizava tomar mais riscos e buscava melhorias financeiras, mas também ocasionava alguns conflitos internos. Além disso, a CooperMaringá apresentava membros com uma melhor formação escolar do que os membros da Cocarema, sendo esse um motivo relevante para que a participação dos membros na autogestão da primeira cooperativa fosse mais ativa do que a participação dos membros da segunda, que sempre atribuíam suas decisões ao líder, ainda que todo o grupo fosse consultado.

Salvi et al. (2011) realizaram, através da coleta de documentos e entrevistas, um mapeamento dos EES em Londrina, identificando três organizações relevantes: a Copersol, apoiada pelo Programa Municipal de Economia Solidária; Cooperativa de Catadores de Materiais Recicláveis e de Resíduos Sólidos da Região Metropolitana de Londrina (Coopersil); Comunidade Doze Tribos, que apresenta uma formação e laços sociais baseados em preceitos cristãos. Os autores apontaram duas dificuldades nessas organizações: a emergência de lideranças informais advinda da omissão da maioria dos integrantes em assumirem responsabilidades e desafios; a dificuldade em ultrapassar a cultura individualista tradicional. A Comunidade Doze Tribos, em particular, se caracterizou por uma maior coesão entre seus membros, garantindo uma forte identidade enquanto grupo e capacidade para desenvolver projetos econômicos em conjunto com elevados padrões motivacionais e de comprometimento. Em uma investigação qualitativa especificamente com os 15 coordenadores das associações que compunham a Coopersil, Luzio dos Santos et al. (2011) verificaram que, mesmo possuindo um 
regimento interno que definia a votação direta como processo de definição dos coordenadores, a escolha do líder da cooperativa era baseada em critérios como "o maior tempo de casa", maior grau de escolaridade ou disposição para assumir responsabilidades. Os relatos foram unânimes em garantir a existência de espaço para todos opinarem e darem sugestões para a condução das atividades, embora os autores salientem que há que se considerar aspectos não formais e subjetivos na maioria dos grupos pesquisados que fazem com que alguns membros possuam maior poder de influência sobre os demais, gerando distorções na relação democrática. Sobre o relacionamento entre os membros das associações, os entrevistados declararam existir um bom relacionamento interpessoal e um certo sentimento de solidariedade por serem todos da mesma origem, serem vizinhos ou mesmo parentes, consolidando as relações de confiança entre eles. Apesar de não haver informações detalhadas sobre a dimensão distributiva, é possível notar que, assim como ocorre com os catadores de resíduos sólidos de Maringá, os membros da Coopersil também não apresentaram uma estrutura organizativa que favoreça a percepção de uma justiça procedimental e interacional que leve a um maior grau de democracia e solidariedade.

Passando a análise geográfica para Pontal do Paraná, a pesca marinha é um exemplo de atividade econômica que, apesar de depender de bens comuns, atualmente se organiza de modo privado, com os pescadores dependendo dos seus meios de produção ou da venda de sua força de trabalho para os proprietários de embarcações. Segundo Caldeira e Pierri (2014), a desigualdade na posse dos meios de produção ocasiona também uma estrutura desigual de remuneração e capacidade de estrutura da pesca, que se apresenta muito heterogênea no território: de pescas artesanais ou de subsistência a empreendimentos empresariais de grande escala para o contexto paranaense. Além disso, a falta de participação e representatividade dos usuários locais, a multiplicidade de vias pelas quais a legislação pesqueira tem sido criada e os problemas de gestão nos diferentes níveis públicos tem ocasionado um quadro institucional inadequado. No intuito de melhorar as condições dos pescadores, os autores defendem a busca de uma reestruturação produtiva baseada em um sistema de parcerias ou de propriedade coletiva dos meios de produção, respeitando os demais preceitos da ES. No entanto, fazem a ressalva de que já houve uma cooperativa na região - Cooperativa dos Pescadores Artesanais do Litoral Paranaense, Coopespar - criada na década de 1980 e que se extinguiu em meados da década de 1990. O insucesso da 
Coopespar é creditado à sua organização realizada "de cima para baixo", que contou com baixa presença e participação dos pescadores nas reuniões, além da falta de orientação e preparo da comunidade, fazendo com que a gestão da organização ficasse a cargo dos técnicos do governo. Além dessa experiência histórica de insucesso, os pesquisadores ressaltaram a existência de um consolidado paradigma de individualismo e os desestímulos às ações coletivas em prol de um bem comum como obstáculos para a construção de uma nova forma de organização social e produtiva. Esse exemplo da pesca marinha em Pontal do Paraná indica não só que a criação de EES deve ser realizada de modo participativo e comunitário para que tenha legitimidade, como também aponta que um eventual fracasso pode dificultar ainda mais a retomada de valores solidários.

Em uma investigação comparativa entre a Cooperativa de Produção Agropecuária (Copavi) de Paranacity e a Cooperativa dos Cafeicultores e Agropecuaristas de Maringá (Cocamar), Chiarello e Eid (2010) mostraram que pode haver muitas diferenças entre cooperativas do mesmo setor. Enquanto a Cocamar claramente se aproxima de uma racionalidade capitalista de organização e gestão que leva os seus membros a se comportarem de maneira individualista em suas relações de cliente, fornecedor e dono com a cooperativa, a Copavi busca manter uma estrutura mais participativa e solidária, incentivando a cultura cooperativa. $\mathrm{O}$ Quadro 2 mostra as principais diferenças entre as duas cooperativas:

\section{Quadro 2 - Gestão dos ativos, finanças, processo decisório e organização do trabalho da Cocamar e Copavi.}

\begin{tabular}{|cc|}
\hline Cocamar & Copavi \\
\hline Desproporção na propriedade de quotas parte & Equidade na propriedade de quotas parte \\
Viés de abertura de capital & Retenção do capital em posse da cooperativa \\
Representatividade da base de sócios é baixa & Representatividade da base de sócios é alta \\
Aplicação da heterogestão & Aplicação da autogestão \\
Prevalece o assalariamento & Prevalece a cooperação \\
Separação entre planejamento e execução & Compactação entre planejamento e execução \\
\hline
\end{tabular}

Fonte: Retirado de Chiarello e Eid (2010), p. 111.

A experiência da Copavi mostra uma aproximação prática das características que ensejam as percepções de justiça de uma ES típica: igualdade, 
democracia e solidariedade. Através de entrevistas com membros da cooperativa, Dos Santos e Vargas (2014) observaram que eles têm a percepção de que as condições de trabalho são boas, o tratamento recebido é igualitário, dizem conviver com pessoas honestas e humildes, que o planejamento de metas e objetivos é realizado por uma autogestão efetiva e que os recursos advindos do trabalho são disponibilizados de acordo com um sistema de horas trabalhadas, sem distinção do tipo de trabalho, dando abertura para que os membros expressem ideias e opiniões sobre novos sistemas distributivos. Os autores notaram que os trabalhadores não sentiam uma perda de autonomia de tomar decisões, exercendo também atividades e funções condizentes com suas formações, o que os mantinham empenhados e motivados na cooperativa. Alguns relatos mostram essas percepções: "Recebemos tratamento adequado e as condições de trabalho são boas e justas, isso nos motiva a trabalhar aqui", "Somos tratados igualmente e com muita justiça" (p.35), "É realizada a definição de metas e objetivos por meio de um planejamento da cooperativa" (p. 36), "Somos empenhados e motivados a atingir as metas que temos que alcançar para que a cooperativa se desenvolva", "Todos participam e podem dar opiniões, as recompensas são bem divididas", "Participamos todos juntos em tudo, e isso que nos faz diferente em relação a outro emprego" (p. 38), "Se desempenho bem meu serviço, me sinto feliz e a cooperativa se desenvolve", "Sou motivada, desempenho melhor o que faço aqui" (p.39). Morais et al. (2011) também confirmaram essas práticas da Copavi, atentando que os cooperados "realizam em seu cotidiano uma participação democrática direta e promove uma nova forma de sociabilidade, bem como produz uma práxis pedagógica que contribui na formação de adultos, jovens e crianças" (p. 161).

Os relatos dos membros da Copavi mostram que boas percepções da justiça em suas três dimensões podem afetar a motivação e o bem-estar dos trabalhadores. Mais do que isso, indica a presença de ações baseadas em comprometimento e estabelece escolhas baseadas em metas coletivas e em objetivos que vão para além do bem-estar, como a busca de um senso de justiça socialmente compartilhado, como proposto por Sen $(1977,2005)$. Assim, as instituições em termos de justiça são extremamente relevantes na definição das aspirações e condutas dos trabalhadores.

Essas observações, ainda que representem apenas uma pequena amostra dos inúmeros EES, apontam para percepções de justiça longe do potencial de 
uma estrutura típica ideal de ES, principalmente nas dimensões procedimentais e interacionais. Ainda há uma presença dominante da individualização das ações, barreiras à participação nas decisões e processos de autogestão, bem como uma percepção de um envolvimento que não é tipicamente comunitário e nem plenamente solidário, o que parece indicar uma dificuldade de transformação das normas, convenções e valores tipicamente capitalistas já enraizados entre os trabalhadores.

\section{Discussão e Considerações Finais}

A partir de uma crítica à noção de justiça distributiva utilitarista incorporada pela economia neoclássica e através da ampliação dimensional do conceito de justiça, foi possível realizar uma investigação no sentido de entender como as três dimensões relevantes da percepção de justiça - distributiva, procedimental e interacional - estão inseridas nas estruturas ideais típicas de Economia Solidária e Economia Capitalista. Ao menos no plano teórico, esperava-se que a ES provesse incentivos à percepção dos trabalhadores em participar de uma economia igualitária, democrática e solidária, com um senso normativo de uma justiça comunitária. No entanto, a observação dos dados do Segundo Mapeamento Nacional de Empreendimentos Econômicos Solidários e dos resultados de estudos com alguns EES do Paraná mostrou que a prática ainda está longe de alcançar os resultados esperados pela teoria, com uma série de desafios percebidos pelos próprios membros das iniciativas solidárias, principalmente nas dimensões da justiça procedimental e interacional. As dificuldades de uma implementação plena de procedimentos democráticos e participativos através da autogestão e o rompimento com os valores individualistas e as instituições tipicamente capitalistas são os principais obstáculos enfrentados para a implementação prática dos preceitos da ES. No entanto, foi possível observar que há possibilidade de sucesso em praticamente todas as dimensões, como é o caso da Copavi. Para além da percepção de uma elevada satisfação e bem-estar dos trabalhadores dessa cooperativa em um ambiente de cooperação solidária, democrática e com distribuição igualitária, observou-se que havia uma preocupação e uma aspiração dos trabalhadores em reconhecer metas coletivas que objetivavam não apenas o bem-estar material, mas alcançar um senso compartilhado de justiça social. Tal concepção comunitária da justiça reflete a importância das obrigações de solidariedade como uma noção de virtude cívica que 
deve ser buscada pelos membros dos EES. Nesse caso, não é apenas a busca da maximização de utilidade ou a defesa de uma liberdade individual de ação mercadológica que garantem aos indivíduos uma percepção de justiça das ações sociais, mas sim como essas ações se relacionam com a própria história de vida que essas pessoas compartilham ou passam a compartilhar ao conviverem em uma iniciativa com princípios e valores solidários.

Há várias possibilidades de avanço no debate levantado por este artigo. Primeiro, pode-se tentar realizar uma aproximação teórica entre a multidimensionalidade das percepções de justiça e a abordagem institucional e de governança comunitária proposta por Elinor Ostrom (1990) dentro de sua discussão sobre ações coletivas, destacando-se a necessidade de ampliar o espectro da teoria econômica para além de uma abordagem meramente utilitarista. Uma segunda possibilidade seria procurar entender se há diferenças nas percepções de justiça não apenas entre estruturas ideais de ES e EC, mas também entre diferentes tipos de empreendimentos econômicos solidários, como levantado por Gaiger et al. (2015). Isso permitiria entender se a percepção de justiça depende de características que vão para além daquelas que definem uma configuração produtiva macroestrutural. Um terceiro caminho de pesquisa seria gerar novos estudos de casos de aplicação direta de indicadores ou variáveis que procurassem mensurar diretamente as três dimensões da percepção de justiça, incluindo a utilização de metodologias quantitativas ${ }^{4}$. Finalmente, uma quarta possibilidade seria expandir a análise geográfica dos EES, observando se há algum tipo de diferença regional no que diz respeito à capacidade que a ES tem em promover uma percepção de igualdade, democracia e solidariedade entre os trabalhadores.

\footnotetext{
${ }^{4}$ Para exemplos de indicadores quantitativos sobre percepções de justiça, ver Beuren et al. (2016) e Dal Vesco et al. (2016).
} 


\section{Referências}

ANAND, P. Procedural fairness in economic and social choice: evidence from a survey of voters. Journal of Economic Psychology, v. 22, p. 247-270, 2001.

BEUREN, I.; KREUZBERG, F.; FRANZ, L. Percepção de justiça processual na avaliação de desempenho: uma análise à luz da incerteza e da tolerância à ambiguidade. Advances in Scientific and Applied Accounting, v. 9, n. 1, p. 3-21, 2016.

BIES, R.; SHAPIRO, D. Interactional fairness judgments: the influence of causal accounts. Social Justice Research, v.1, n. 2, p. 199-218, 1987.

BRASIL. Ministério do Trabalho e Emprego. III Conferência Nacional de Economia Solidária - texto de referência. Brasília, 2014.

CALDEIRA, G.; PIERRI, N. As relações econômicas e a gestão compartilhada de recursos comuns: o caso da pesca marinha em Pontal do Paraná, Sul do Brasil. Desenvolvimento e Meio Ambiente, v. 32, p. 119-137, 2014.

CHIARELLO, C.; EID, F. Singularidades na gestão de cooperativas tradicionais e populares: estudo de caso em cooperativas rurais do Paraná. Organizações Rurais e Agroindustriais, v. 12, n. 1, p. 98-112, 2010.

CRUZ, A. Redes de economia solidária - papéis e limites de atores envolvidos: trabalhadores, universidade e estado. Seminario Internacional La Co-construcción de Conocimientos y prácticas Sobre La Economia Social y Solidaria em América Latina y Canadá, Centro de Estudios de Sociologia del Trabajo, Universidad de Buenos Aires, v. 24, 2009.

DAL VESCO, D.; BEUREN, I.; POPIK, F. Percepção de justiça na avaliação de desempenho e satisfação do trabalho. Enfoque: Reflexão Contábil, v. 35, n. 3, p. 121-138, 2016.

DEQUECH, D. Economic institutions: explanations for conformity and room for deviation. Journal of Institutional Economics, v. 9 (1), p. 81-108, 2013.

DEQUECH, D. Neoclassical, Mainstream, Orthodox, and Heterodox Economics. Journal of Post Keynesian Economics, v. 30, n. 2, p. 279-302, 2007.

DOS SANTOS, J.; VARGAS, E. Um estudo sobre a motivação no ambiente organizacional de uma cooperativa de produção agropecuária do município de Paranacity - PR. Caderno de Administração, v. 22, n. 1, p. 28-42, 2014.

FLEISCHACKER, S. Uma breve história da justiça distributiva. São Paulo: Martins Fontes, 2006. 
FOLGER, R. Distributive and procedural justice: combined impact of voice and improvement on experienced inequity. Journal of Personality and Social Psychology, v. 35, n. 2, p. 108-119, 1977.

FREY, B.; POMMEREHNE, W. On the fairness of pricing: an empirical survey among the general population. Journal of Economic Behavior and Organization, v. 20, p. 295-307, 1993.

FREY, B.; STUTZER, A. Happines, economy and institutions. The Economic Journal, v. 110, p. 918-938, 2000.

GAIGER, L. Antecedentes e Expressões Atuais da Economia Solidária. Revista Crítica de Ciências Sociais, v. 84, p. 81-99, 2009.

GAIGER, L.; FERRARINI, A.; VERONESE, M. Social enterprise in Brazil: an overview of solidarity economy enterprises. Retrieved February, v. 13, 2015.

LAVILLE, J. Economia solidária, a perspectiva europeia. Sociedade e Estado, v. 16, n. 1-2, p. 57-99, 2001.

LAZEAR, E. Economic imperialism. The Quarterly Journal of Economics, v. 115 n. 1, p. 99-146, 2000.

LEE, J.; LEE, H. Human capital and income inequality. Journal of The Asia Pacific Economy, v. 23, n. 4, p. 554-583, 2018.

LEVENTHAL, G. What should be done with equity theory? New approaches to the study of fairness in social relationships. 1976. Disponível em: <https://eric.ed.gov/?id=ED142463>. Acesso em: 08 fev. 2019.

LUSTIG, N.; LOPEZ-CALVA, L.; ORTIZ-JUAREZ, E. Deconstructing the decline in inequality in Latin America. In: BASU, K.; STIGLITZ, J. (eds.). Inequality and Growth: Patterns and Policy, v. 1. Londres: Palgrave Macmillian: 2016.

LUZIO DOS SANTOS, L.; LIMA, J.; FERREIRA, T. Parceria entre economia solidária e poder público: avanços e desafios da COOPERSIL. In: LUZIO DOS SANTOS, Luís; BORINELLI, B.; PITAGUÁRI, S. (eds.). Economia solidária numa pluralidade de perspectivas, Londrina UEL: 2011.

MAS-COLELL, A.; WHINSTON, M.; GREEN, J. Microeconomic Theory. Oxford: Oxford University Press, 1995.

MAZZEI, B.; CRUBELATTE, J. Autogestão em empreendimentos econômicos solidários: um estudo comparativo de casos em cooperativas de reciclagem de lixo em Maringá - PR. Revista Inteligência Organizacional, v. 1, n. 1, p. 43-61, 2011. 
MOLM, L.; COLLETT, J.; SCHAEFER, D. Conflict and fairness in social exchange. Social Forces, v. 84, n. 4, p. 2331-2352, 2006.

MONTE, C.; PARENTE, T.; MIRANDA, C. Interfaces entre gênero e economia solidária: a partir de um grupo de mulheres em Miracema do Tocantins/TO. Seminário de Desenvolvimento Regional, Estado e Sociedade. Palmas: UFT, 2018.

MORAIS, E.; LANZA, F.; LUZIO DOS SANTOS, L.; PELANDA, S. Cooperativismo e economia solidária: teoria e prática na COPAVI Paranacity PR. In: LUZIO DOS SANTOS, L.; BORINELLI, B.; PITAGUÁRI, S. (eds.), Economia solidária numa pluralidade de perspectivas, Londrina UEL: 2011.

NOZICK, R. Anarchy, State and Utopia. Nova Iorque: Basic Books, 1974.

OLIVEIRA, J.; TAKANO, J.; SANTOS, L.; DUTRA, I. Princípios de economia solidária em cooperativas de catadores de resíduos sólidos de Maringá - PR: Avanços, Desafios e Limitações. Revista Perspectivas Contemporâneas, v. 11, n. 3, p. 79-96, 2016.

OLSTROM, E. Governing the commons: the evolution of institutions for collective actions. Cambridge University Press, 1990.

PIKETTY, T. O Capital no Século XXI. Rio de Janeiro: Intrínseca, 2014.

RAWLS, J. Some reasons for the maximin criterion. The American Economic Review, v. 64, n. 2, p. 141-146, 1974.

SALVI, I.; BANSI, A.; MARTOS, S.; LUZIO DOS SANTOS, L. O mapa dos empreendimentos de economia solidária de Londrina - PR. In: LUZIO DOS SANTOS, L.; BORINELLI, B.; PITAGUÁRI, S. (eds.). Economia solidária numa pluralidade de perspectivas, Londrina UEL: 2011.

SANDEL, M. Justiça. O que é fazer a coisa certa. Rio de Janeiro: Civilização Brasileira, 2012.

SEN, A. Rational fools: a critique of the behavioral foundations of economic theory. Philosophy \& Public Affairs, v. 6, n. 4, p. 317-344, 1977.

SEN, A. Why exactly is commitment important for rationality? Economics and Philosophy, v. 21, n. 1, p. 5-13, 2005.

SINGER, P. Introdução à Economia Solidária. São Paulo: Fundação Perseu Abramo, 2002.

SISTEMA NACIONAL DE INFORMAÇÕES EM ECONOMIA SOLIDÁRIA. Segundo Mapeamento Nacional de Empreendimentos Econômicos Solidários. http://sies.ecosol.org.br/atlas. 2013. 
THIBAULT, J.; WALKER, L.; LATOUR, S.; HOULDEN, P. Procedural justice as fairness. Stanford Law Review, v. 26, n. 6, p. 1271-1289, 1974.

VARIAN, H. Microeconomia-princípios básicos: uma abordagem moderna. Rio de Janeiro: Campus, 2006.

WEBER, M. Economy and Society: a new translation. Cambridge: Harvard University Press, 2019. 